Supporting Information for

\title{
Partitioning of the Vibrational Free Energy
}

\author{
Dmitri G. Fedorov,
}

Research Center for Computational Design of Advanced Functional Materials (CD-FMat),

National Institute of Advanced Industrial Science and Technology (AIST), Central 2,

Umezono 1-1-1, Tsukuba, 305-8568, Japan. 

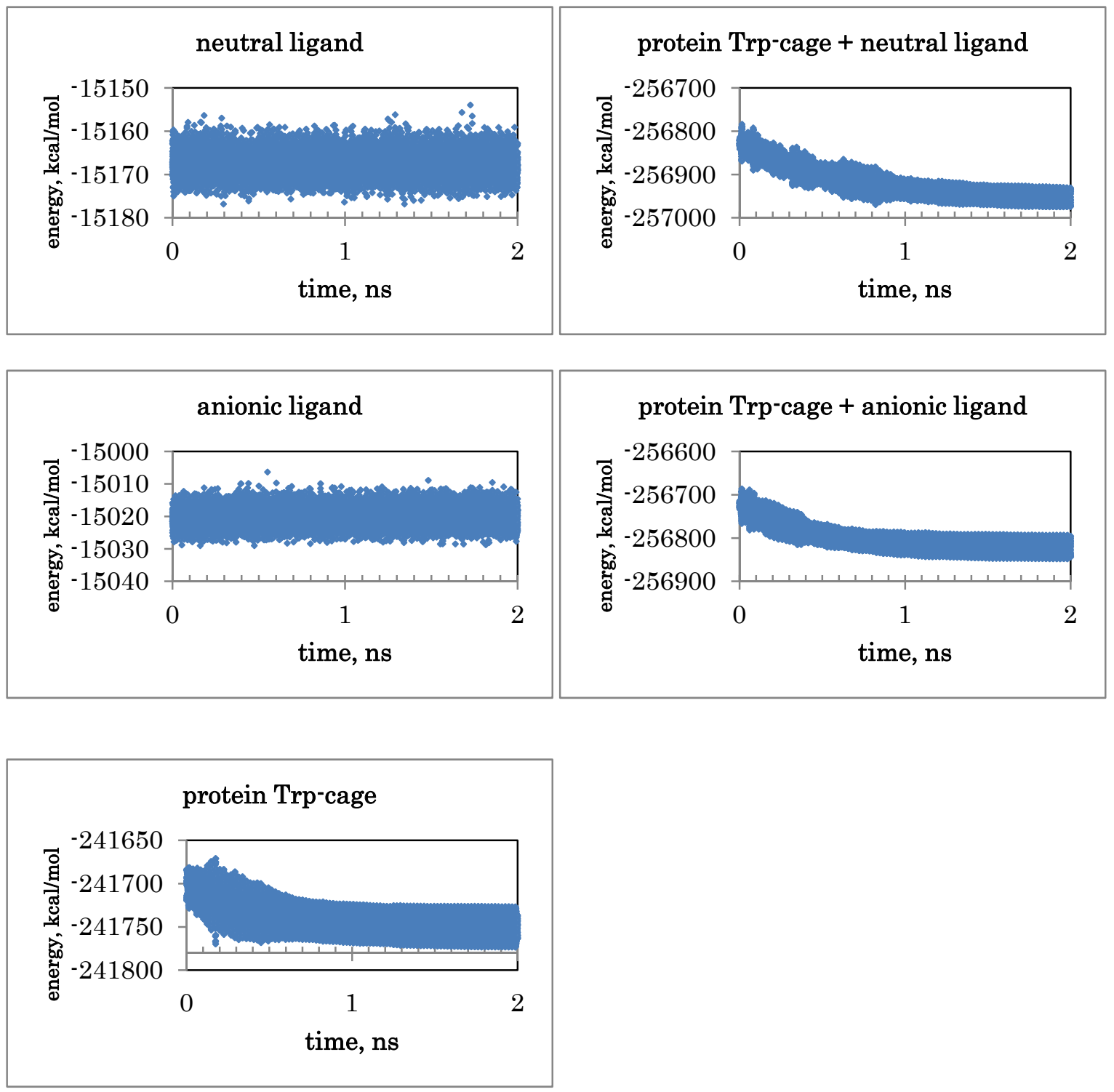

Figure S1. Fluctuations of the potential energies in FMO2-DFTB3 NVT MD simulations. 
The derivation of eq 19 is as follows.

$F_{a}^{\text {vib }}=\frac{R h v_{a}}{2 k}+R T \ln \left(1-\exp \left(-h v_{a} / k T\right)\right)=0$

Introducing $x=\frac{h v_{a}}{k T}$,

$-\frac{x}{2}=\ln (1-\exp (-x))=0$

$\exp (-x / 2)=1-\exp (-x)$

Introducing $y=\exp (-x / 2)$,

$y=1-y^{2}$

$y=\frac{-1+\sqrt{5}}{2}$

$\ln y=-\frac{x}{2}=\ln \left(\frac{\sqrt{5}-1}{2}\right)$

$x=-2 \ln \left(\frac{\sqrt{5}-1}{2}\right)=\frac{h v_{a}}{k T}$

$v_{a}=\frac{2 k T}{h} \ln \left(\frac{2}{\sqrt{5}-1}\right)$ 